\title{
Diferentes doses de ciclofosfamida no sistema imune de ovinos
}

\author{
Different dosis of cyclophosphamide on the ovine immune system
}

\author{
Maurício Garcia $^{1}$ Sabrina Caruso Chate ${ }^{2}$ Ana Carolina Rusca Porto ${ }^{3}$ \\ Yara Ferreira Figueira ${ }^{3}$ André Dias Diegues ${ }^{3}$ Flávia Corbari Feres $^{3}$ \\ Maria de Fátima Martins ${ }^{2}$
}

\section{RESUMO}

O objetivo deste trabalho foi avaliar o efeito de diferentes doses de ciclofosfamida como indutor de imunossupressão experimental em ovinos. Foram empregados 30 animais, divididos em quatro grupos experimentais. Os animais dos grupos I, II e III foram submetidos, respectivamente, às doses de 10, 25 e 40 mg kg-1 e os do grupo IV não receberam a droga, permanecendo como controle. Todos os animais foram imunizados com vacina contra a brucelose e, seis dias após a vacinação, foi feita a titulação através da soroaglutinação rápida em placa. Foi feita também a contagem de linfócitos sangüíneos e a dosagem de gamaglobulinas séricas, diariamente, durante uma semana, após a aplicação da ciclofosfamida. Houve óbitos apenas em alguns animais do grupo III (40mg $\left.\mathrm{kg}^{-1}\right)$. Assim, a droga mostrou-se segura com doses inferiores a $25 \mathrm{mg} \mathrm{kg}^{-1}$. Quanto à imunossupressão, a mesma pôde ser demonstrada tanto nos animais que receberam $25 \mathrm{mg} \mathrm{kg}^{-1}$, quanto aqueles que receberam $40 \mathrm{mg} / \mathrm{kg}$, através da análise dos resultados das contagens de linfócitos e dos títulos pós-vacinais anti-brucela. A dose de $25 \mathrm{mg}$ $\mathrm{kg}^{-1}$ de ciclofosfamida mostrou-se, assim, a mais adequada para ser usada em modelos de imunodepressão em ovinos, considerando sua ação imunossupressora e sua segurança $e$ toxicidade.

Palavras-chave: ciclofosfamida, imunossupressão, ovinos.

\section{ABSTRACT}

The purpose of the present work was to evaluate different dosis effect of cyclophosphamide (CY) as an immunosuppressor in ovine. Thirty animals were grouped into four categories: groups I, II and III received 10, 25 e 40mg kg-1 of $C Y$ and group IV remained as control. All animals were immunized with brucelosis vaccine and six days after that, serum agglutination test was performed. During one week, blood lymphocyte count and gammaglobulin serum concentration were also daily evaluated. Deaths occured only in group III $\left(40 \mathrm{mgkg}^{-1}\right)$, so the drug seems to be safe in dosis under $25 \mathrm{mg} \mathrm{kg}^{-1}$. Immunosuppression was found both in groups II $(25 \mathrm{mg} / \mathrm{kg})$ and III (40mg kg-1), as it could be found in blood lymphocyte count and serum agglutination test. Authors concluded that $25 \mathrm{mg} \mathrm{kg}$ is the most adequate dosis to use CY for experimental immunosuppression models in ovine, considering the immunosuppression effect, safety and toxicity.

Key words: cyclophosphamide, immunosuppression, ovine.

\section{INTRODUÇÃO}

A ciclofosfamida é uma mostarda nitrogenada usada no tratamento de diversos tipos de câncer. A droga é um potente imunodepressor, atuando em células com alta atividade mitótica, inibindo tanto a resposta imune humoral quanto celular (BACH \& STROM, 1986). Em ovinos, esse efeito também foi relatado por alguns autores, tal como JUN \& JOHNSON (1979), PRASAD et al. (1986) e GARCIA et al. (2002). Diversos protocolos para o uso da ciclofosfamida em ovinos têm sido propostos, com diferentes propósitos, com doses variando de 10 a $50 \mathrm{mg} \mathrm{kg}^{-1}$, tanto via oral quanto intravenosa (DOLNICK et al., 1969, 10 a 30 $\mathrm{mg} \mathrm{kg}^{-1}$; MCINTOSH et al., 1971, 30mg kg-1; BAKKE et al., 1972, 30mg $\mathrm{kg}^{-1}$; JACKSON et al., 1975, 10 a 30mg kg-1;

${ }^{1}$ Médico Veterinário, professor do curso de Medicina Veterinária da Universidade Paulista, Atualmente Vice-Reitor da Universidade Anhembi Morumbi. E-mail: mgarcia@anhembi.br

${ }^{2}$ Médico Veterinário do Curso de Medicina Veterinária da Universidade Paulista.

${ }^{3}$ Estudante do Curso de Medicina Veterinária da Universidade Paulista. 
BOGDANOV \& KUSNEDELCHEVA, 1977, 25mg $\mathrm{kg}^{-1}$; GORDON, 1982, 10mg kg ${ }^{-1}$; PRASAD et al., 1986, 50 $\mathrm{mg} \mathrm{kg}^{-1}$ ). O objetivo deste trabalho foi avaliar o efeito de diferentes doses de ciclofosfamida como indutor de imunossupressão experimental em ovinos.

\section{MATERIAL E MÉTODOS}

Trinta ovinos adultos, machos, castrados, com peso ao redor de $30 \mathrm{~kg}$, isentos de vermes, mantidos estabulados em baias e alimentados com feno de coast-cross e feno de alfafa foram empregados. Os animais foram alocados em quatro grupos experimentais. Os animais dos grupos I, II e III (seis animais por grupo) foram submetidos a diferentes doses de ciclofosfamida (Genuxal, Asta Médica), aplicada via intravenosa, em dose única, no dia zero (10, 25 e 40 $\mathrm{mg} \mathrm{kg}^{-1}$ respectivamente). Os do grupo IV (12 animais) não receberam a droga, permanecendo como controle. No dia zero, todos os animais foram imunizados com $2 \mathrm{~mL}$ de vacina contra a brucelose, amostra B19 (Aborvac, Fort Dodge), por via subcutânea. Seis dias após a vacinação, foi feita a titulação de anticorpos anti-brucela, através da soroaglutinação rápida em placa, segundo padronização feita por GARCIA et al. (2000b).

A contagem de linfócitos sangüíneos e a dosagem de gamaglobulinas séricas foram realizadas diariamente, durante uma semana, após a aplicação da ciclofosfamida. A contagem de linfócitos foi calculada multiplicando-se o valor da contagem total de leucócitos, determinada em contador eletrônico, pela contagem diferencial, obtida em extensão sangüínea corada (HEWITT, 1984). A dosagem total de gamaglobulinas séricas foi calculada multiplicando-se o seu valor percentual pela dosagem de proteínas totais, obtida pelo método do biureto (WEICHSELBAUM, 1946). O valor percentual de gamaglobulinas foi determinado por eletroforese em gel de agarose, sendo o filme lido em densitômetro (DS 50, Celm) a 520mm. (BARTA \& POURCIAU, 1984).

Foram registrados os óbitos decorrentes da aplicação da droga, sendo calculada a taxa de mortalidade em cada grupo experimental. Os dados foram analisados estatisticamente por análise de variância, seguida do teste t "student". As taxas de mortalidade foram analisadas pelo teste do quiquadrado (ZAR, 1996). Foi considerado um valor de $p=5 \%$. Foi empregada planilha eletrônica comercial (Excel 97, Microsoft) de acordo com as recomendações de DRETZKE \& HEILMAN (1998).

\section{RESULTADOS}

Na dose de $40 \mathrm{mg} \mathrm{kg}^{-1}$, a ciclofosfamida mostrou-se bastante tóxica, causando a mortalidade de $50 \%$ dos animais tratados. Não houve mortalidade nos demais grupos. No que ser refere à capacidade de bloquear a síntese de anticorpos pós-vacinais, notouse o efeito da ciclofosfamida nos animais tratados com 25 e com $40 \mathrm{mg} \mathrm{kg}^{-1}$, os quais apresentaram títulos vacinais estatisticamente menores que os demais grupos (Tabela 1).

Quanto à variação diária das contagens linfocitárias, notou-se que os animais tratados com 25 e $40 \mathrm{mg} \mathrm{kg}^{-1}$ apresentaram quedas expressivas em suas contagens, atingindo os menores valores ao redor do 5o dia após a aplicação da droga. Já os animais tratados com $10 \mathrm{mg} \mathrm{kg}^{-1}$ não apresentaram variações estatisticamente significantes quando comparados com os animais do grupo controle (Tabela 2). No que se refere à dosagem de gamaglobulinas, não foram encontradas diferenças estatisticamente significantes entre os grupos estudados (Tabela 3).

\section{DISCUSSÃO}

Houve óbitos em $50 \%$ animais do grupo III (40 $\left.\mathrm{mg} \mathrm{kg}^{-1}\right)$. A droga mostrou-se segura com doses inferiores a $25 \mathrm{mg} \mathrm{kg}^{-1}$. Quanto à imunossupressão, a mesma pôde ser demonstrada tanto nos animais que receberam $25 \mathrm{mg} \mathrm{kg}^{-1}$ quanto naqueles que receberam $40 \mathrm{mg} \mathrm{kg}^{-1}$, através da análise dos resultados das contagens de linfócitos e dos títulos pós-vacinais antibrucela. Esses resultados reforçam os achados de JUN \& JOHNSON (1979), PRASAD et al. (1986) e GARCIA et al. (2002), os quais relataram o efeito imunossupressor da droga. Entretanto, a dose de $10 \mathrm{mg} \mathrm{kg}^{-1}$ não conseguiu

Tabela 1 - Títulos de anticorpos pós-vacinais em ovinos imunizados com vacina contra a brucelose e tratados com diferentes doses de ciclofosfamida via intravenosa, em dose única, no dia da imunização (média e desvio padrão).

\begin{tabular}{lc}
\hline Dose de ciclofosfamida & Título \\
\hline $10 \mathrm{mg} \mathrm{kg}^{-1}$ & $53,3^{\mathrm{a}}$ \\
& $( \pm 31,1)$ \\
$25 \mathrm{mg} \mathrm{kg}^{-1}$ & $7,8^{\mathrm{b}}$ \\
& $( \pm 1,9)$ \\
$40 \mathrm{mg} \mathrm{kg}^{-1}$ & $1,4^{\mathrm{b}}$ \\
& $( \pm 1,9)$ \\
controle & $47,1^{\mathrm{a}}$ \\
& $( \pm 28,9)$ \\
\hline
\end{tabular}

${ }^{\mathrm{ab}}$ letras iguais indicam valores estatisticamente iguais

Ciência Rural, v.34, n.6, nov-dez, 2004. 
Tabela 2 - Variação percentual diária da contagem de linfócitos sangüíneos em ovinos tratados com diferentes doses de ciclofosfamida via intravenosa, em dose única, no dia zero (média e desvio padrão).

\begin{tabular}{|c|c|c|c|c|c|c|c|c|}
\hline Dose & Dia 0 & Dia 1 & Dia 2 & Dia 3 & Dia 4 & Dia 5 & Dia 6 & Dia 7 \\
\hline $10 \mathrm{mg} \mathrm{kg}^{-1}$ & $\begin{array}{l}100 \%^{a} \\
( \pm 0 \%)\end{array}$ & $\begin{array}{c}75 \%{ }^{\text {ac }} \\
( \pm 34 \%)\end{array}$ & $\begin{array}{r}79 \%^{a} \\
( \pm 24 \%)\end{array}$ & $\begin{array}{r}75 \%{ }^{a} \\
( \pm 16 \%)\end{array}$ & $\begin{array}{r}71 \%^{a} \\
( \pm 19 \%)\end{array}$ & $\begin{array}{c}70 \%^{\mathrm{a}} \\
( \pm 20 \%)\end{array}$ & $\begin{array}{r}85 \%^{a} \\
( \pm 23 \%)\end{array}$ & $\begin{array}{r}89 \% \%^{a} \\
( \pm 27 \%)\end{array}$ \\
\hline $25 \mathrm{mg} \mathrm{kg}^{-1}$ & $\begin{array}{l}100 \%^{\mathrm{a}} \\
( \pm 0 \%)\end{array}$ & $\begin{array}{c}61 \%{ }^{a b} \\
( \pm 30 \%)\end{array}$ & $\begin{array}{c}45 \%^{\mathrm{b}} \\
( \pm 22 \%)\end{array}$ & $\begin{array}{c}49 \%{ }^{a b} \\
( \pm 31 \%)\end{array}$ & $\begin{array}{c}29 \%^{\mathrm{b}} \\
( \pm 14 \%)\end{array}$ & $\begin{array}{r}24 \%^{\mathrm{b}} \\
( \pm 11 \%)\end{array}$ & $\begin{array}{l}25 \%^{\mathrm{b}} \\
( \pm 9 \%)\end{array}$ & $\begin{array}{c}29 \%{ }^{b} \\
( \pm 10 \%)\end{array}$ \\
\hline $40 \mathrm{mg} \mathrm{kg}^{-1}$ & $\begin{array}{l}100 \%^{a} \\
( \pm 0 \%)\end{array}$ & $\begin{array}{c}32 \%{ }^{\mathrm{b}} \\
( \pm 21 \%)\end{array}$ & $\begin{array}{c}24 \%^{\mathrm{b}} \\
( \pm 14 \%)\end{array}$ & $\begin{array}{c}19 \%^{\mathrm{b}} \\
( \pm 11 \%)\end{array}$ & $\begin{array}{c}21 \%{ }^{\mathrm{b}} \\
( \pm 13 \%)\end{array}$ & $\begin{array}{c}14 \%^{\mathrm{b}} \\
( \pm 4 \%)\end{array}$ & $\begin{array}{c}23 \%{ }^{\mathrm{b}} \\
( \pm 11 \%)\end{array}$ & $\begin{array}{c}20 \%^{\mathrm{b}} \\
( \pm 11 \%)\end{array}$ \\
\hline controle & $\begin{array}{l}100 \%{ }^{a} \\
( \pm 0 \%)\end{array}$ & $\begin{array}{c}99 \%{ }^{c} \\
( \pm 36 \%)\end{array}$ & $\begin{array}{c}106 \%{ }^{a} \\
( \pm 48 \%)\end{array}$ & $\begin{array}{c}69 \% \%^{a} \\
( \pm 24 \%)\end{array}$ & $\begin{array}{c}71 \%{ }^{a} \\
( \pm 25 \%)\end{array}$ & $\begin{array}{c}82 \%{ }^{a} \\
( \pm 33 \%)\end{array}$ & $\begin{array}{c}75 \%{ }^{a} \\
( \pm 29 \%)\end{array}$ & $\begin{array}{r}70 \% \\
( \pm 30 \%)\end{array}$ \\
\hline
\end{tabular}

${ }^{\mathrm{abc}}$ letras iguais indicam valores estatisticamente iguais (na mesma coluna)

Tabela 3 - Variação percentual diária da dosagem de gamaglobulinas séricas em ovinos tratados com diferentes doses de ciclofosfamida via intravenosa, em dose única, no dia zero (média e desvio padrão).

\begin{tabular}{|c|c|c|c|c|c|c|c|c|}
\hline Dose & Dia 0 & Dia 1 & Dia 2 & Dia 3 & Dia 4 & Dia 5 & Dia 6 & Dia 7 \\
\hline $10 \mathrm{mg} \mathrm{kg}^{-1}$ & $\begin{array}{l}100 \%^{a} \\
( \pm 0 \%)\end{array}$ & $\begin{array}{r}89 \%^{a} \\
( \pm 16 \%)\end{array}$ & $\begin{array}{r}94 \%^{a} \\
( \pm 19 \%)\end{array}$ & $\begin{array}{l}92 \%^{a} \\
( \pm 5 \%)\end{array}$ & $\begin{array}{r}90 \%{ }^{a} \\
( \pm 11 \%)\end{array}$ & $\begin{array}{c}102 \%^{a} \\
( \pm 11 \%)\end{array}$ & $\begin{array}{l}96 \%^{a} \\
( \pm 6 \%)\end{array}$ & $\begin{array}{r}97 \%^{a} \\
( \pm 10 \%)\end{array}$ \\
\hline $25 \mathrm{mg} \mathrm{kg}^{-1}$ & $\begin{array}{c}100 \%^{a} \\
( \pm 0 \%)\end{array}$ & $\begin{array}{c}107 \%^{\mathrm{a}} \\
( \pm 18 \%)\end{array}$ & $\begin{array}{r}77 \%{ }^{a} \\
( \pm 10 \%)\end{array}$ & $\begin{array}{c}99 \%{ }^{\mathrm{ab}} \\
( \pm 17 \%)\end{array}$ & $\begin{array}{r}85 \%^{a} \\
( \pm 10 \%)\end{array}$ & $\begin{array}{r}87 \%^{a} \\
( \pm 14 \%)\end{array}$ & $\begin{array}{c}76 \%{ }^{\mathrm{b}} \\
( \pm 9 \%)\end{array}$ & $\begin{array}{r}91 \%{ }^{a} \\
( \pm 11 \%)\end{array}$ \\
\hline $40 \mathrm{mg} \mathrm{kg}^{-1}$ & $\begin{array}{l}100 \%^{a} \\
( \pm 0 \%)\end{array}$ & $\begin{array}{c}101 \%^{\mathrm{a}} \\
( \pm 21 \%)\end{array}$ & $\begin{array}{r}84 \%{ }^{a} \\
( \pm 14 \%)\end{array}$ & $\begin{array}{r}85 \%^{\mathrm{a}} \\
( \pm 12 \%)\end{array}$ & $\begin{array}{r}95 \%^{\mathrm{a}} \\
( \pm 12 \%)\end{array}$ & $\begin{array}{r}93 \%^{\mathrm{a}} \\
( \pm 17 \%)\end{array}$ & $\begin{array}{c}84 \%{ }^{a b} \\
( \pm 15 \%)\end{array}$ & $\begin{array}{r}79 \%{ }^{\mathrm{a}} \\
( \pm 12 \%)\end{array}$ \\
\hline controle & $\begin{array}{l}100 \%^{a} \\
( \pm 0 \%)\end{array}$ & $\begin{array}{c}104 \%{ }^{a} \\
( \pm 16 \%)\end{array}$ & $\begin{array}{c}90 \%^{\mathrm{a}} \\
( \pm 28 \%)\end{array}$ & $\begin{array}{l}111 \% \text { b } \\
( \pm 18 \%)\end{array}$ & $\begin{array}{c}103 \%{ }^{a} \\
( \pm 22 \%)\end{array}$ & $\begin{array}{c}103 \%{ }^{a} \\
( \pm 15 \%)\end{array}$ & $\begin{array}{c}92 \%{ }^{a} \\
( \pm 12 \%)\end{array}$ & $\begin{array}{l}100 \%{ }^{\mathrm{a}} \\
( \pm 18 \%)\end{array}$ \\
\hline
\end{tabular}

${ }^{\mathrm{ab}}$ letras iguais indicam valores estatisticamente iguais (na mesma coluna)

reproduzir o quadro de imunossupressão. Esse resultado não confirma, assim, os estudos de DOLNICK et al. (1969), JACKSON et al. (1975) e GORDON (1982).

Apesar de os animais que receberam doses igual ou acima de $25 \mathrm{mg} \mathrm{kg}^{-1}$ estarem com seu sistema imune comprometido, não foi encontrada uma diminuição nos níveis séricos de gamaglobulinas, conforme havia sido relatado por YEGANA et al. (1983). Esses resultados sugerem que o nível de anticorpos séricos pode não ser um indicador tão bom quanto a contagem de linfócitos, fenômeno também encontrado por SILVA et al. (2001).

\section{CONCLUSÕES}

A dose de $25 \mathrm{mg} \mathrm{kg}^{-1}$ de ciclofosfamida mostrou-se a mais adequada para ser usada em modelos de imunodepressão em ovinos, considerando sua ação imunossupressora e sua segurança e toxicidade.

\section{REFERÊNCIAS BIBLIOGRÁFICAS}

BACH, J.F.; STROM, T. The mode of action of immunosuppressive agents. Amsterdam : Elsevier, 1986.

BAKKE, J.E. et al. Metabolism of cyclophosphamide by sheep. J Agr Food Chem, v.20, n.2, p.384-388, 1972.

BARTA, O.; POURCIAU, S.S. Electrophoreis. In: BARTA, O. Laboratory techniques of veterinary clinical immunology. Illinois : Charles C. Thomas, 1984. p.116-122.

BOGDANOV, M.; KUSNEDELCHEVA, S. Chemical and hematologic studies of sheep before and after treatment with cyclosphamide. Vet Med Nauki, v.14, n.5, p.87-91, 1977.

DOLNICK, E.H. et al. Cyclophosphamide as a chemical “defleecing” agent for sheep. Nature, v.221, n.179, p.467-468, 1969. 
DRETZKE, B.J.; HEILMAN, K.A. Statistics with Microsoft ${ }^{\circledR}$ Excel. New Jersey : Practice Hall, 1998. 164p.

GARCIA, M. et al. Titulação de anticorpos anti Brucella abortus em ovinos experimentalmente imunizados. In: CONGRESSO BRASILEIRO DE MEDICINA VETERINÁRIA, 27., 2000, Águas de Lindóia. Anais... São Paul o: Sociedade Paulista de Medicina Veterinária, 2000. p.70.

GARCIA, M. et al. Experimental induction and evaluation of immunosuppression in ovine. In: WORLD BUIATRICS CONGRESS, 22., 2002, Hanover. Proceedings... Hanover: German Buiatrics Association, 2002. p.194.

GORDON, A.J. Effect of dexamethasone and cyclophosphamide on urinary hydroxyproline to creatinine ratios in sheep. Australian Journal of Biology Science, v.35, n.2, p.153-161, 1982.

HEWITT, S.G. Haematology. In: GRAY, D.E. Manual of veterinary investigation, laboratory techniques. 3.ed. London: Her Majesty’s Stationery Office, 1984. V.2, p.72-100.

JACKSON, C.J. et al. Effect of cyclosphophamide on erythrocyte and plasma acetycholinesterase activity in sheep. Journal of Animal Science, v. 41, n. 5, p. 1390-1393, 1975.

JUN, M.H.; JOHNSON, R.H. Effect of cyclophosphamide on tumour growth and cell- mediated immunity in sheep with ovine squamous cell carcinoma. Research in Veterinary Science, v.27, n.2, p.155-160, 1979 .

McINTOSH, G.H. et al. Cyclophosphamide in the treatment of mycotic dermatitis of sheep. Australian Veterinary Journal, v.47, p. 542-546, 1971 .

PRASAD, G. et al. Effect of cyclophosphamide on immune response of sheep against attenuated sheep pox virus. Indian Journal of Experimental Biology, v.24, n. 11, p.692-695, 1986.

SILVA, M.M. et al. Efeito da verminose na resposta imune humoral em caprinos. In: CONGRESSO BRASILEIRO DE MEDICINA VETERINÁRIA, 28., 2001, Salvador. Anais... Salvador : Sociedade Baiana de Medicina Veterinária, 2001. p.118-119.

WEICHSELBAUM, C.T.E. An accurate and rapid method for determination of proteins in small amounts of blood serum and plasma. American Journal of Clinical Pathology, v.16, n.3, p.40-49, 1946.

YEGANA, Y. et al. Changing pattern of the serum proteins in asymptomatic sheep treated with cyclophosphamide for chemical shearing. British Veterinary Journal, v.139, p.415422, 1983.

ZAR, J.H. Biostatistical analysis. 3.ed. New Jersey : Practice Hall, 1996. 662p. 